\title{
IZABEL DOS SANTOS: EDUCAÇÃO PARA A VIDA
}

Rita Sório 1

Izabel é uma daquelas pessoas especiais, que, com certeza, deixam sua marca junto daqueles com os quais se relaciona. Profundamente sábia, é doutora no que fala e discute, não por ter feito essa ou aquela pós-graduação, mas acima de tudo por ter sabido saborear o melhor da vida e, como ela mesmo afirma, o melhor do trabalho. Em nossa conversa ocorrida em novembro, com a finalidade de gerar a entrevista que faz parte deste registro histórico na Trabalho, Educação e Saúde, Izabel começa e termina afirmando isso: nunca fui uma teórica!!!

Não pensem que é avessa às discussões teóricas (eu diria que sabe filosofar como ninguém), mas de fato respeita muito o pensamento que foi formulado a partir da experiência das pessoas, do vivido, principalmente daquilo que é fruto da ação do homem, daquilo que é produzido pelo homem. É, sem dúvida, uma mulher apaixonada e apaixonante, o que torna para nós, os amigos, e, porque não dizer, seus discípulos, esta tarefa muito árdua. Melhor e mais justo seria que um poeta viesse a produzir estas linhas, afinal, ela é Musa, não tem jeito. Como Musa, tem o dom de nos encantar a todos com suas histórias, suas propostas e seus pontos de vista.

Fiquei muito intimidada com a perspectiva de fazer uma homenagem a Izabel dos Santos por dois motivos: o primeiro é que sabemos, quem convive com ela, que é totalmente avessa a esse tipo de coisa. Não gosta, nunca gostou, e eu até já assisti a determinadas má-criações dela em público, o maior "vexame"; segundo, eu não teria condições de falar de Izabel, de sua vida aqui neste espaço, não tenho dados suficientes para isso, demandaria uma pesquisa imensa e, cá para nós, recentemente Izabel foi homenageada com um livro, a ser lido por todos que se interessam pela nossa história, pela história de nossa gente e da saúde pública no Brasil. É um livro cuja 

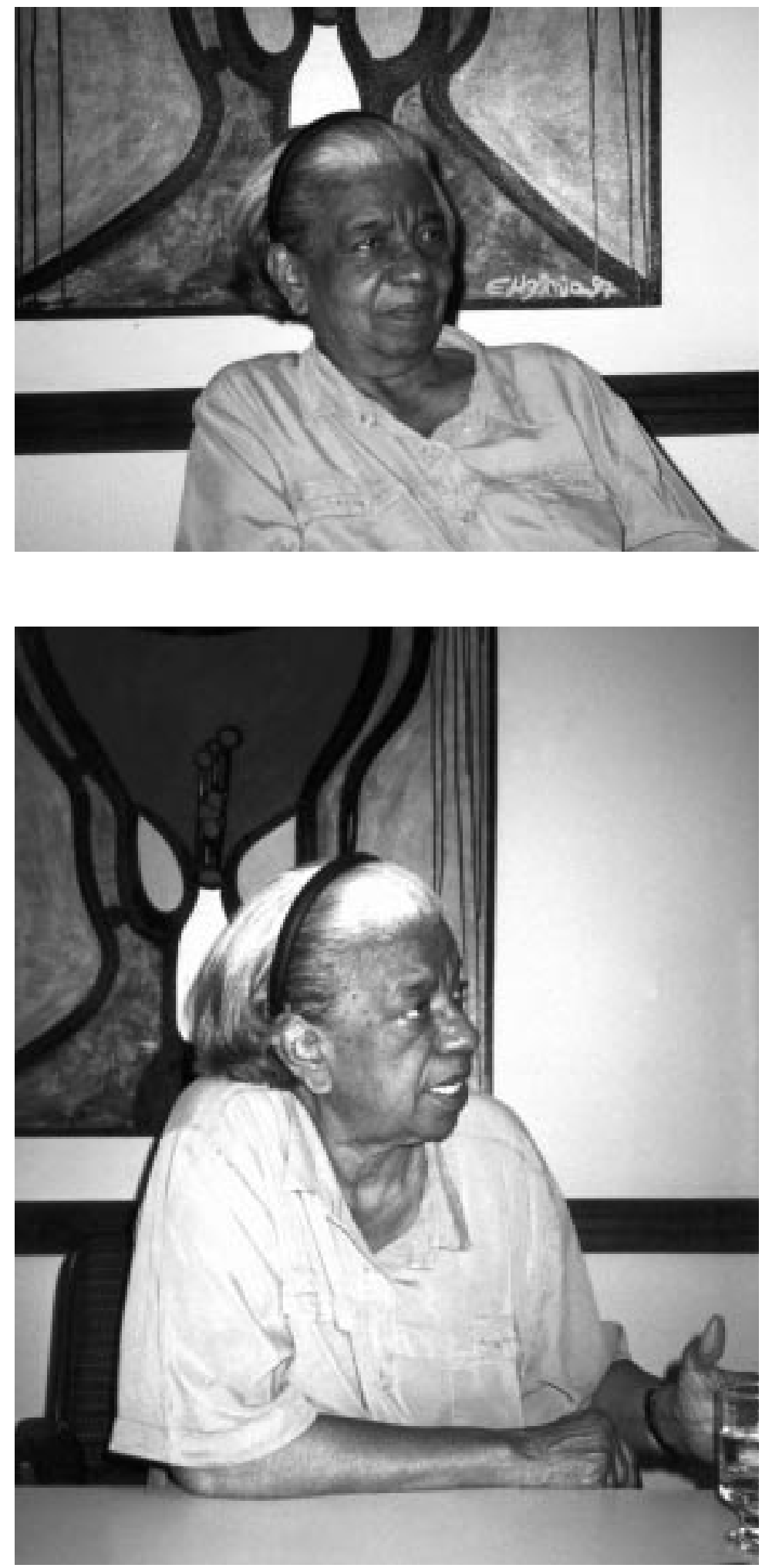

Izabel dos Santos 
maior beleza está no conteúdo dos depoimentos da própria Izabel e de alguns companheiros de jornada que conviveram com ela no trabalho. Estou me referindo à obra Izabel dos Santos: a arte e a paixão de aprender fazendo, de autoria de Janete Castro, José Paranaguá e Roberto Nogueira. Eles, principalmente os dois últimos, estiveram com ela há muitos anos em projetos de longa data! Ali se pode saber muito mais sobre quem é Izabel.

Conheci Izabel dos Santos em 1989, sou amiga das novas, acho eu! Eu já ouvira falar dela, porque fazia parte do grupo de profissionais que estava envolvido no Curso de Desenvolvimento de Recursos Humanos em Saúde (CADRHU) - proposta da Organização Pan-americana de Saúde (OPAS) para formar gerentes de recursos humanos na área de saúde. Quando em vez, em algum lugar do Brasil afora por onde andava, ouvia falar de Izabel dos Santos. As referências eram quase sempre relacionadas à metodologia pedagógica inovadora utilizada no Projeto Larga Escala.

Este Projeto, hoje assumido pela própria Izabel como uma estratégia que se tornou um movimento social, envolvendo milhares de pessoas, foi pensado no âmbito do setor saúde, com o objetivo de proporcionar a inclusão de milhares de trabalhadores, em sua maioria mulheres, garantindo-lhes as condições de exercerem uma profissão na qual já trabalhavam como leigas. Esta proposta foi constituída sobre alguns pilares essenciais: uma nova concepção de escola orientada para o sujeito, utilizando metodologias participativas no processo ensino-aprendizagem, a partir da problematização; o trabalho como eixo do processo educativo, rompendo a dicotomia das disciplinas e do aprendizado para algo ou sobre algo; e um processo de formação de formadores que ousava desfazer e 're-fazer' os conteúdos cristalizados e preconcebidos das chamadas licenciaturas, tornando possível um 'reconhecimento' do agente da aprendizagem frente ao aluno, por princípio, trabalhadores com déficits em sua formação por falta de oportunidades e pelas condições de vida. Izabel foi mestre de todos nós, pois, antes de muita gente, já era escolada nestas questões.

Como Izabel também participara da elaboração da proposta do CADRHU, pois era funcionária da OPAS no Brasil, tinha uma certa curiosidade em conhecê-la. Até porque também não era incomum ouvir alguém falando de seus rompantes e suas broncas junto a turmas de professoras que se preparavam para trabalhar com a metodologia da problematização. Crescia minha curiosidade.

Pois foi com essas informações que um dia em Brasília, participando da Conferencia Nacional de Recursos Humanos, conheci Izabel dos Santos. Fiquei completamente atordoada, pois ela era muito irreverente, engraçada, desbocada e ácida. Do tipo que não perdoava nada! Estive em seu grupo de trabalho, e o mais fascinante para mim foi seu jeito muito especial de levar o grupo a refletir. Ela não deixava passar questão alguma sem ser discutida, 
compreendida, debatida. E, em nenhum momento, se furtou ao debate por mais conflituoso que fosse: — "Não tem essa história de colocar no Relatório porque é assim não, temos que saber se as pessoas aqui estão entendendo, apoiando" e por aí vai. Então pensei, essa era a Professora Izabel dos Santos!

Nossa amizade e proximidade também foram construídas a partir do trabalho e por razões que foram dadas ou conduzidas em parte pelo destino, nunca vamos entender bem como foi mesmo que as coisas se deram. Mas o fato é que, durante vários momentos da década de 90, tive a oportunidade de trabalhar em projetos junto com Izabel dos Santos. A convivência, muitas vezes tumultuada, sempre foi prazerosa e, acima de tudo, de aprendizado e troca. Izabel dos Santos é uma mestra e uma artesã. Sabe como ninguém fazer e refazer seu ponto de vista ou sua opinião, desde que esteja convencida de sua importância na condução e no resultado de determinada ação.

A sua capacidade de reconstruir e fazer uma idéia sobreviver, a despeito das conjunturas e dificuldades, é invejável. Esta é uma marca que considero indelével na sua personalidade! Para mim, sua força e energia são renovadas justamente quando é desafiada a criar, ou a tornar clara uma idéia, uma proposta em que ela acredite! Mas a que idéias me refiro? Eu diria que Izabel dedicou toda a sua vida para ampliar o acesso das pessoas, especialmente dos trabalhadores de nível médio em saúde, ao conhecimento. Foram anos e anos dedicados à luta por garantir o direito à profissionalização de milhares de pessoas.

Neste percurso, nunca optou pelo caminho mais fácil, mas sim pelo que pudesse proporcionar, ao mesmo tempo, inclusão social para aqueles que tinham déficit educacional, numa perspectiva integrada à melhoria dos serviços de saúde. Assim é que o processo de formação veio acompanhado de uma concepção de escola, de um projeto de capacitação de docentes, de uma proposta de profissionalização crítica, progressista, jamais conformada com a situação desfavorável que acometia esses trabalhadores. Durante décadas, esse processo foi amadurecido, testado, polido, e como ela mesma faz questão de dizer na entrevista publicada neste número da Trabalho, Educação e Saúde, é um processo em aberto, que foi sendo influenciado pelo próprio movimento de organização do setor e por seus desafios; "na verdade, o que eu queria era possibilitar que as pessoas pudessem compreender os fenômenos do mundo do trabalho, não só decorar as causas disso ou daquilo (...) isso não se faz com os cursinhos e treinamentos, é um processo que depende de maturação".

Em 1995, já trabalhando na Escola Politécnica de Saúde Joaquim Venâncio, comecei a ter uma convivência mais amiúde com ela, porque desenvolvíamos o Projeto Escola, com apoio da OPAS. Os recursos financeiros, con- 
seguidos em uma articulação com Paulo Buss, então Vice-Presidente de Ensino da Fundação Oswaldo Cruz, no Rio de Janeiro, na gestão de Carlos Morel, não eram muitos, mas representaram um input importante na consolidação do sonho de Izabel: fortalecer um conjunto de escolas e centros formadores de saúde que pudessem proporcionar a formação pública e de qualidade a todos os trabalhadores do Sistema Único de Saúde (SUS). Ali pude constatar pessoalmente a felicidade de Izabel!

Quando discutíamos as dificuldades, muitas relacionadas à assimetria de conhecimentos e à fragilidade institucional dos estados, ela me dizia com os olhos brilhantes, cheia de luz: "olha, não me importa se temos poucos recursos, o que mais me deixa alegre, feliz mesmo, é que estamos envolvendo uma nova geração nessa história". Era impossível não se deixar contaminar por sua alegria! E pude perceber o quanto ela tinha de visão estratégica.

Para mim, esse período foi de intenso aprendizado. O que mais me chamou a atenção foi a sua capacidade de trabalhar com os diferentes e com as diferenças. Era tão importante para ela, na sua visão estratégica, associar a Escola Politécnica à Rede de Escolas Técnicas do SUS, que pude observar Izabel exercendo ao máximo sua capacidade negociadora, criativa e, acima de tudo, mantendo um compromisso respeitoso e generoso com todos com quem ia trabalhando. Também para ela, creio foi algo importante e acho que foi o aprendizado alcançado entre todos que construíam o Projeto Escola que fez daquela proposta uma experiência ímpar.

Durante os anos seguintes, e a partir de 1998, acontece algo inesperado e, mais uma vez, fomos impelidas a trabalhar juntas. O Ministério da Saúde propõe a elaboração e a implantação de um projeto nacional, de grande envergadura, com o objetivo de profissionalizar todos os trabalhadores de enfermagem, que atuavam nos serviços de saúde sem a devida qualificação profissional. Era definitivamente a oportunidade de Izabel ver realizada, na devida escala, o grande objetivo de toda sua vida. Poucos acreditaram ser possível realizar o Projeto de Profissionalização dos Trabalhadores da Área de Enfermagem (PROFAE), mas fato é que o Projeto foi desenhado, negociado e implantado em todos os estados, com um alto grau de inovação do ponto de vista educacional e gerencial.

É inegável a contribuição, nesse processo, das idéias de Izabel dos Santos. Não creio que caiba falar disso aqui, até por minhas implicações e responsabilidades à frente do Projeto referido, mas não posso deixar de registrar um lado muito pessoal dessa história: as lembranças de longos momentos discutindo idéias interessantes sobre a formação dos trabalhadores de saúde.

Foram incontáveis noites em sua casa, bastante agradáveis, em que varávamos a madrugada entre discussões e prosa. Nesse período, vivia eu entre Rio e Brasília, e quase sempre me hospedava na casa de Izabel. Nosso co- 
tidiano era marcado por calorosos debates acerca da educação profissional, sobre o futuro da esquerda, sobre os excluídos, sobre a atenção à saúde.

Enfim, discutíamos sobre muitos assuntos de nosso interesse. Izabel é acolhedora e, muitas vezes, tínhamos em sua casa pessoas de vários estados, amigos seus de longa data. A qualidade de suas idéias e a forma de argumentar sobre seus pontos de vista me fizeram, não raras vezes, repensar coisas, não só do trabalho, mas da vida também. Mas o mais interessante era sua capacidade de vibrar com nossas vitórias! Afinal, nunca fez parte de nossa tradição governamental, muito menos setorial, alocar grandes recursos para a formação, muito menos para formação de profissionais de saúde. Mas, sem dúvida, a força de seus argumentos, calcados na prática e na experiência real com a formação, conquistou a todos, inclusive a ala dos economistas e engenheiros que à época ocupavam cargos de direção no Ministério.

E, assim, seguimos com nossa amizade, que vai muito além da afinidade pelas causas comuns e pela defesa da educação profissional em saúde. Acho que, sem dúvida, a paixão pela vida e pelas pessoas é um dos segredos de seu sucesso. Mas, com certeza, Izabel traz consigo a força de sua origem mineira, das veredas e chapadas longínquas, dos povos que vivem a vida à margem do São Francisco, o que, associado às suas raízes afro-descendentes, resultou em uma fé inabalável nos homens e nas possibilidades de transformação de suas condições existenciais.

Deixo, por fim, o leitor em companhia de Izabel dos Santos, por ela mesma, a partir de entrevista a mim concedida em 8 de novembro de 2003, em que é possível entrever sua paixão pelo trabalho e seu amor pela educação profissional em saúde.

\section{Nota}

1 Professora licenciada da Fundação Oswaldo Cruz, especialista do Setor Social no Banco Interamericano de Desenvolvimento - BID no Brasil, Mestre em Saúde Pública pela Escola Nacional de Saúde Pública/Fiocruz. <rsorio@fiocruz.br>.

\section{Referência bibliográfica}

CASTRO J. L.; PARANAGUÁ, J. S.; NOGUEIRA, R. P. 2003. Izabel dos Santos: a arte e a paixão de aprender fazendo. Natal: Editora Observatório RH-Nesc/UFRN. 